\title{
A (IN) CONSTITUCIONALIDADE DA REINCIDÊNCIA E A VONTADE DE PUNIR DO ESTADO ANTE O IUS PUNIENDI
}

\section{THE (IN) CONSTITUTIONALITY OF RECIDIVISM AND THE WILL TO PUNISH THE STATE BEFORE IUS PUNIENDI}

\author{
Murilo Cabral de Paulo Marcolino ${ }^{1}$, Luan Felipe Silva Sobrinho ${ }^{2}$, Juliano de O. Leonel ${ }^{3}$
}

Submetido em: 04/05/2021

e24271

Aprovado em: 25/05/2021

\section{RESUMO}

O instituto da reincidência advém da preocupação estatal com a satisfação dos anseios sociais, que resulta em reprovar com maior rigor a habitualidade na prática criminosa, sendo, então, uma forma mais rígida de reprovação social em que, ao indivíduo, confere-se um aumento de pena na nova condenação. Em face a esse cenário, o presente estudo se destinou a analisar, à luz da lei, da doutrina e da jurisprudência, a (in) constitucionalidade da agravante ante as garantias fundamentais previstas na vigente Carta Federal, de modo que se possa entender os motivos que levam a crer na falha do Estado em educar, violando princípios constitucionalmente estabelecidos. Assim, foi desenvolvido por meio de buscas literárias que englobaram dois tipos de abordagens distintas, quais sejam a dedutiva e dialética, dando ao leitor a chance de averiguar entendimentos e que resultam numa perspectiva que vai de encontro ao que é tido, comumente, no saber cotidiano. $\mathrm{O}$ objeto se refere à resposta à usualidade delitiva que, no entanto, falhou em atingir o objetivo da prevenção, o que recai sobre o indivíduo, que se vê punido de forma mais rígida para atingir os desejos da massa populacional. Por fim, conclui-se que a agravante advém da teoria antigarantista, que destoa dos princípios basilares previstos no corpo constitucional.

PALAVRAS-CHAVE: Reincidência. Inconstitucionalidade. (Re) socialização.

\begin{abstract}
The institute of recidivism comes from the state concern with the satisfaction of social expectations, which results in disapproving more rigorously the habitual criminal practice, being, then, a stricter form of social disapproval in which is given to the individual an increase of penalty in the new conviction. Considering this scenario, the present study aimed to analyze, in the light of the law, of the doctrine and of the jurisprudence, the (un) constitutionality of the aggravating circumstance in view of the fundamental guarantees provided in the current Federal Constitution, in order to understand the reasons that indicate the failure of the State to educate, violating constitutionally established principles. Thus, it was developed through literary researches that embraced two different types of approaches, deductive and dialectical, giving the reader the chance to check agreements and which result in a perspective that goes against what is usually had in daily knowledge. The object applies to the response to the criminal frequency that, however, failed to achieve the goal of prevention, which falls on the individual, which is punished more strictly to achieve the desires of the population mass. Finally, it is concluded that the aggravating circumstance comes from the theory against garantism, which disagrees with the basic principles provided by the constitutional structure.
\end{abstract}

KEYWORDS: Recidivism. Unconstitutionality. (Re)socialization.

\footnotetext{
${ }^{1}$ Centro Universitário Santo Agostinho - UNIFSA

2 Centro Universitário Santo Agostinho - UNIFSA

${ }^{3}$ Professor Mestre em Direito pela Universidade Católica de Brasília
} 


\section{RECIMA21 - REVISTA CIENTÍFICA MULTIDISCIPLINAR ISSN 2675-6218}

A (IN) CONSTITUCIONALIDADE DA REINCIDÊNCIA E A VONTADE DE PUNIR DO ESTADO ANTE O IUS PUNIENDI Murilo Cabral de Paulo Marcolino, Luan Felipe Silva Sobrinho

\section{INTRODUÇÃO}

O instituto da reincidência, no Direito Penal, vem sendo objeto de diversos debates e divergências no âmbito das ciências criminais, não somente no campo teórico-científico, mas, também, na prática forense, em audiências nos tribunais. O fato de ser essa uma forma de expressão da reprovação social ao indivíduo que, mesmo após o trânsito em julgado de sentença condenatória, volta a delinquir demonstra a preocupação do Estado em atingir a satisfação das expectativas sociais, reprovando com maior rigor a habitualidade criminal.

A Reincidência encontra amparo legal nos artigos 61, inciso I, 63 e 64 do Código Penal Brasileiro (1940), ainda se mostrando subtendida como circunstância geral no artigo 59 da mesma codificação em comento. O objetivo da circunstância agravante é conferir um aumento na segunda condenação do agente, em virtude de uma condenação anterior já transitada em julgado.

O instituto penal objeto desta pesquisa é justificado pela continuidade delitiva do agente, isto é, uma vez que a pena aplicada pelo Estado não restou suficiente para intimidar o delinquente e, tampouco, ressocializá-lo, aplica-se um plus ao cômputo da nova pena.

De fato, é necessário punir o indivíduo que pratica conduta ilícita. Mas até que ponto seria justo, do modo de ver humanitário e levando em consideração os tratados dos quais o Brasil é signatário, utilizar o modo de vida, bem como as características do delinquente para justificar o uso da agravante para o cálculo da nova pena? Seria a reincidência uma desculpa estupefata do Estado para justificar a falha do caráter preventivo da pena e, assim, promover um estado ad aeternum de marginalização aos condenados? Estaria o Estado punindo, desta vez com maior rigor, o delinquente pela conduta ora praticada, ou pelas máculas pessoais do mesmo? A que ponto uma punição mais rigorosa pode fazer com que o delinquente habitual compreenda que errou e, daí, possa trilhar o seu caminho de "redenção"? Seria a agravante inconstitucional por violar garantias fundamentais como: dignidade da pessoa humana, proporcionalidade, (non) bis in idem?

Destarte, insta acrescentar que a agravante possui influências do Direito Penal do Autor - uma teoria antigarantista em que os delinquentes são punidos por suas máculas pessoais, e não pelo crime cometido, que serviria apenas de iniciativa ao Estado para perseguir e aplicar a pena -, bem como da ideia de periculosidade do agente que delinque habitualmente.

Diante disso, cumpre analisar o instituto da reincidência, bem como a sua (in)compatibilidade com o Estado Democrático de Direito, tão enraizado na vigente Constituição Federal (1988), uma vez que a agravante promove uma constante criminalização ad aeternum ao agente, maculando sua honra e imagem frente à sociedade ao carregar os estigmas oriundos da nova condenação, fato esse que justifica a ineficiência do Estado no que se refere ao dever de reeducar e ressocializar aquele intitulado criminoso.

O presente estudo analisou, à luz da lei, dos entendimentos doutrinários e jurisprudenciais, a (in) constitucionalidade da agravante penal ante as garantias fundamentais consagradas no texto 


\section{RECIMA21 - REVISTA CIENTÍFICA MULTIDISCIPLINAR ISSN 2675-6218}

A (IN) CONSTITUCIONALIDADE DA REINCIDÊNCIA E A VONTADE DE PUNIR DO ESTADO ANTE O IUS PUNIENDI Murilo Cabral de Paulo Marcolino, Luan Felipe Silva Sobrinho

Constitucional. Do mesmo modo, os motivos contundentes que levaram a crer na falha educacional do Estado, assim como, também, na função repressiva, de maneira a violar os princípios fundamentais.

Constatou-se, também, que a circunstância agravante é resultante das influências da Teoria do Direito Penal do Autor e, por consequência, é incompatível com o sistema penal garantista, à medida que as justificativas irracionais sustentam a legalidade do instituto, implicando a falha do Estado no que concerne ao caráter ressocializador da pena, contribuindo para a promoção de estigmas sociais sobre aquele delinquente que, após suportar uma condenação, torna a delinquir.

\section{DA REINCIDÊNCIA}

\subsection{Conceito}

À luz do vigente Código Penal, respectivamente em seu art. 63 e seguintes, verifica-se a reincidência quando o agente comete novo crime, depois de transitar em julgado a sentença que, no país ou no estrangeiro, o tenha condenado por crime anterior. Trata-se de uma circunstância agravante de pena, percebida pelo magistrado na segunda fase da dosimetria penal, cujo principal requisito para a sua verificação é: uma condenação pretérita já transitada em julgado.

O critério é bastante objetivo, não importando se a condenação se deu em solo nacional ou internacional, tampouco se o crime fora praticado na modalidade dolosa ou culposa, mas, desde que seja verificado o período depurador de 05 (cinco) anos existente entre a condenação pretérita e a nova (art. 64, I, CP/40), isto é, caso a nova condenação alcance o status de trânsito em julgado dentro de 05 (cinco) anos da condenação anterior, há hipótese de reincidência. Do contrário, não há que se falar em aumento de pena pela agravante em comento (CIRINO, 2014).

\subsection{Das Finalidades das Penas e Relação com a Reincidência}

O atual Código Penal brasileiro consagrou, em seu art. 59, a Teoria Mista, no tocante às finalidades da pena. Portanto, denota-se que a pena tem precípua finalidade de reprovar o injusto penal, aplicando uma sanção ao agente em decorrência de um crime; e prevenir, numa faceta geral, que novas infrações sejam praticadas; bem como, numa faceta especial, desestimular a continuidade delitiva do agente promovendo a sua reeducação.

Embora a função preventiva da pena, em seu caráter especial, tenha finalidade utilitarista, consistindo em fazer o agente perceber que violou os valores da ordem jurídica e, desse modo, não volte a delinquir, devendo ser reintegrado à sociedade, ocorre que nem sempre a aplicação penal fora tão romantizada. A história das penas guarda uma trajetória terrível, cruel e dotada de caráter vingativo, sem qualquer preocupação com a promoção da justiça (CUNHA, 2016). As penas eram executadas em locais públicos, servindo de estímulo para a não ocorrência de novos crimes, e assistidas por aqueles que se deleitavam, com prazer, ao ver reprovação do "mal” praticado. 


\section{RECIMA21 - REVISTA CIENTÍFICA MULTIDISCIPLINAR ISSN 2675-6218}

A (IN) CONSTITUCIONALIDADE DA REINCIDÊNCIA E A VONTADE DE PUNIR DO ESTADO ANTE O IUS PUNIENDI Murilo Cabral de Paulo Marcolino, Luan Felipe Silva Sobrinho

No que tange à acentuada punição promovida pela Reincidência, em relação às funções da pena, percebe-se que a agravante atribui um plus na segunda condenação do agente, em virtude de uma condenação pretérita transitada em julgado. O raciocínio é bem simples: se o castigo não restou suficiente para incutir temor e arrependimento naquele agente já sentenciado, acentua-se a sua pena na próxima condenação.

Ocorre que, nesse sentido, a justificativa para a legalidade do instituto é irracional. A agravante se mostra contrária à função preventiva da pena, falhando com a finalidade ressocializadora (GRECO, 2017), respondendo com maior rigor, acentuando a punição daquele que, talvez, nunca fora socializado, promovendo um "processo de criminalização" (CIRINO, 2014) ${ }^{1}$, pois, à guisa da segregação do agente ao cárcere e, consequentemente, do estigma social que irá suportar, o Estado afasta o agente da (re)socialização, indo na contramão do objetivo fundamental da Constituição Federal - erradicar a marginalização e reduzir desigualdades -, previsto em seu art. $3^{\circ}$, inciso III.

Outrossim, Zaffaroni e Pierangeli $(2011)^{2}$ entendem que a recidiva seria uma incidência da falha Estatal, no critério preventivo especial da pena, pois a agravante restaria uma "ofensa" à imagem soberana do Estado e, como consequência, a pena da nova condenação será acrescida em face da primeira.

Todavia, os avanços da delinquência, bem como a insatisfação com as decisões judiciais, fazem nascer a vontade de punir na sociedade que anseia uma maior reprovabilidade dos criminosos pelo Estado - o chamado populismo penal -, o qual, mormente, estimula a criação de mecanismos de segregação dos direitos daqueles rotulados "marginais". Sob essa ótica, constata-se que a agravante seria um instrumento contribuinte para o "pagamento" da conduta delitiva praticada.

\subsection{Das Influências do Direito Penal do Autor na Recidiva}

Diante deste cenário, no qual a punição cumpre a função de castigar, de vingar, com fundamento desregrado nos dizeres populares de "pagar pelo que fez" ou "que a justiça seja feita" em que pouco importa o arrependimento do delinquente -, é que nascem as teorias antigarantistas, in casu, a Teoria do Direito Penal do Autor.

A princípio, antes de tecer as considerações a respeito da aludida teoria, é imperioso conceituar a Teoria do Direito Penal do Fato, segundo a qual a punição do agente se dá em resposta à prática de um fato delitivo apenado com sanção expressamente prevista em lei, sendo as suas características pessoais irrelevantes para que o Estado efetue o seu ius puniendi (MASSON, 2017).

\footnotetext{
${ }^{1}$ A falha do Estado na função preventiva da pena implica a acentuação da reprovação do delinquente e, por tamanha razão, deveria o legislador classificar a reincidência como circunstância atenuante, visto o incentivo à habitualidade criminosa oriunda dos efeitos da agravante.

${ }^{2}$ Acrescenta-se que, ao tornar a delinquir, o agente não lesa, tão somente, o bem jurídico tutelado pelo direito penal, mas, também, a imagem do Estado como provedor da segurança jurídica. (Manual de Direito Penal Brasileiro, p. 718).
} 

ISSN 2675-6218

Com efeito, na eventualidade do agente ter incorrido na prática de um crime previsto em lei, será processado e julgado de acordo com a gravidade da lesão ao bem juridicamente tutelado. De igual maneira ocorrerá a aplicação e execução da pena.

De forma adversa à teoria em comento, a Teoria do Direito Penal do Autor defende a necessidade de serem levadas em consideração as características do agente para que haja a efetiva reprovação do mal praticado, assim como a prevenção do perigo que aquele delinquente representa à sociedade.

Nesse sentido, corroboram Zaffaroni e Pierangeli (2002, p. 110) que o direito penal do autor "(...) é uma corrupção do direito penal, em que não se proíbe o ato em si, mas o ato como manifestação de uma 'forma de ser' do autor, esta sim considerada verdadeiramente delitiva”. Em outras palavras, a teoria pugna a necessidade de se punir o delinquente pela pessoa que é, não pelo que fez.

O conceito guarda íntima ligação com o critério de "periculosidade", ao qual é atribuindo ao agente em detrimento da prática delitiva, ocasionando a suposição do reincidente ser mais perigoso que aquele primário, implicando afirmar que o critério confere uma presunção absoluta, pouco importando as causas que levaram a reincidência (CHIQUEZI, 2009).

Nota-se que periculosidade implica um juízo de certeza, oriundo de um direito penal autoritário, cuja personalidade do autor do delito é critério para conferir o status de perigoso àquele que delinquente habitual (KARAM, 1994).

$\mathrm{E}$, nesse sentido, a marca de "perigoso" cairá sobre o agente, principalmente àquele que torna a reincidir na vida delitiva, que será mais uma vez segregado ao ambiente prisional, sendo forçoso afirmar que estará mais distante da sua ressocialização - ou no caminho de uma aprimoração dos dons delitivos (LOMBROSO, 1876) ${ }^{3}$.

Desta feita, destaca-se que a teoria vai ao desencontro do Garantismo Penal, entranhado na vigente Constituição Federal, pois, ao passo em que o sistema de garantias promove uma maior proteção às liberdades individuais, minimizando a violência e ampliando a liberdade, a teoria do direito penal do autor favorece maior segregação do delinquente, violando a sua dignidade, levando em consideração as características do agente. Ademais, não se pode pensar em um Direito Penal justo, isonômico e equitativo se este acaba por valorar a persona do agente, deixando-se levar por presunções, ao invés de focar na conduta a ser reprovada, velando pela criação de estigmas sociais, separando os civilizados dos não civilizados (STRECK, 2001).

Tecidas tais considerações, atesta-se que a figura da reincidência é produto da teoria em comento, pois o agente sofre uma condenação por conta de sua vida pregressa e, por conta desta, a

\footnotetext{
${ }^{3} \mathrm{O}$ cárcere é uma escola para aqueles que se inseriram na vida criminosa, onde são formadas novas alianças entre os presos - ou não - e, portanto, a reincidência do agente à prisão seria uma espécie de instrumento que promoveria um melhor aprimoramento das técnicas delitivas, fazendo do cárcere uma verdadeira faculdade, onde "o agressor se transforma em falsário, o ladrão em estelionatário ou moedeiro falso".
} 

ISSN 2675-6218

segunda pena lhe é aumentada sob o argumento da "contramotivação", para não delinquir, quando, na verdade, está apenas dificultando a reinserção daqueles já marcados.

\section{A MORAL COMO NORTEADORA DA VONTADE DE PUNIR}

Conforme elevam-se os ânimos sociais no que diz respeito ao aumento das práticas criminosas, eleva-se, também, a exigência por segurança pública, unida ao sentimento de vingança nascido e crescido nos populares através do tempo. A consequência disso é a necessidade de punir com mais rigidez aquele que comete o crime, pois o Estado não deve fechar os olhos para aqueles que perturbam a ordem dos bons.

Com isso, é possível inferir que tal ordem se associa à moral do povo, ou seja, que essa vigente no momento determina o que é certo ou errado, ou quem é bom ou mau. Do mesmo modo, também decide se pune mais gravemente ou não e, claro, com o fito de servir de exemplo para os demais.

A respeito dessa moral, partindo de uma análise histórica e sociológica, claro, levando em consideração os fatores determinantes de cada tempo, Nietzsche afere que possui um fundo de segregação. Melhor dizendo, que houve em certo tempo (tantos outros afirmam que ainda existe) a distinção de moral correta e errada (NIETZSCHE, 1887).

A distinção entre categorias se deu em um passado histórico sombrio, esquecido até mesmo por aqueles que se beneficiam até hoje em razão dele. Com efeito (que atravessou gerações, inclusive), originalmente, foi atribuído às ações não egoístas o caráter de "boas" por aqueles que as faziam. Assim, o autor da ação era quem intitulava se era boa ou ruim!

Por coincidência (ou não), aqueles que classificavam as atitudes eram os nobres, detentores do poder, muitas vezes ligados à igreja, todos esses que faziam a distinção da boa conduta (nobre, honrável, digna de louros) e da má (plebeia, vulgar, de baixo nível). Ademais, consoante Nietzsche (1887), é latente na história do conceito de boa moral a figura do racismo, que, atribuída aos ideais da época, trazia o "homem bom" como sendo aquele louro, nobre, puro, em distinção do "homem mau", aquele de pele escura, cabelos negros, que não faz parte da nobreza.

A outro tanto, a visão cristã daquilo que seria posto como correto acabou por influenciar de forma intensa a sociedade da época que, claro, tratou de passar adiante suas doutrinas até o presente período, tão tal que ainda se usa seus conceitos na atualidade. A ideia de ir contra a natureza humana e pregar os ideais de bondade, piedade e a crença no "juízo final" como forma de vingança para com aqueles que excederam a margem imposta e de recompensa (salvação) para os "bons" demonstram em apertada síntese o que engloba todo esse conceito.

\subsection{A vontade cruel de punir do Estado}




\section{RECIMA21 - REVISTA CIENTÍFICA MULTIDISCIPLINAR ISSN 2675-6218}

A (IN) CONSTITUCIONALIDADE DA REINCIDÊNCIA E A VONTADE DE PUNIR DO ESTADO ANTE O IUS PUNIENDI Murilo Cabral de Paulo Marcolino, Luan Felipe Silva Sobrinho

Ao entender a base histórica da moral, pode-se falar, ainda, da vontade/necessidade de punir aqueles que não se encaixam no padrão. Ora, se o fundamento nobre dos homens de classe são os ideais cristãos, que justificam e louvam aqueles comportamentos distintos à sua natureza, nada seria de se estranhar que o próprio fulcro das punições impostas aos delinquentes é o mesmo que o dos homens de classe. Desse modo, assevera Nietzsche (1887, p. 36):

Foi com ajuda de tais invenções que a vida conseguiu então realizar a arte em que sempre foi mestra: justificar a si mesma, justificar o seu "mal"; agora ela talvez necessite de outros inventos (por exemplo, vida como enigma, vida como problema do conhecimento). "É justificado todo mal cuja visão distrai um deus": assim falava a primitiva lógica do sentimento - e apenas a primitiva? Os deuses como amigos de espetáculos cruéis — oh, até onde essa antiquíssima ideia ainda hoje não permeia a nossa humanização europeia!

E é nessa perspectiva que se justificam os atos punitivos como necessários à adequação do delinquente na sociedade cristã. Aliás, os castigos, por servirem de exemplos, eram realizados em locais públicos, de modo que todos vissem o criminoso pagar por seus pecados. Enquanto isso, os bondosos homens de paz, aqueles que detinham boa condição financeira, assistiam, vendo, no castigo do outro, a vingança que almejavam.

Vale dizer, ainda, que o sentido de castigo era justamente esse (mas moldável conforme os tempos), de produzir em quem assiste à sensação de que a justiça foi feita. Ainda nas palavras de Nietzsche (1887, p. 43):

Castigo como neutralização, como impedimento de novos danos. Castigo como pagamento de um dano ao prejudicado, sob qualquer forma (também na de compensação afetiva). Castigo como isolamento de uma perturbação do equilíbrio, para impedir o alastramento da perturbação. Castigo como inspiração de temor àqueles que determinam e executam o castigo. Castigo como espécie de compensação pelas vantagens que o criminoso até então desfrutou (por exemplo, fazendo-o trabalhar como escravo nas minas). Castigo como segregação de um elemento que degenera (por vezes de todo um ramo de família, como prescreve o direito chinês: como meio de preservação da pureza da raça ou de consolidação de um tipo social).

O castigo é motivo de festa, de ultraje, de comemoração ao ver que aquele que causou mal ao ambiente moralmente correto foi punido. O castigo serve, também, para ficar na memória daquele que delinquiu, de modo que seja tão tal que o indivíduo não voltará a delinquir. É, também, o castigo que extrai, no autor do dano, o remorso, o sentimento de culpa, de estar errado em não se adequar, errado por não constituir os requisitos necessários para fazer parte dos homens bons.

Todavia, a contrario sensu daqueles que justificam de tal forma, o sentimento de remorso no delinquente foi o que menos se pôde observar. Assim, o poder punitivo do Estado, criado por aqueles que ansiavam pela ordem correta das coisas, mostrou-se falho desde os primórdios da sociedade até os dias de hoje, pois, dentre aqueles que sofriam os castigos, pouco se viu semelhança qualquer do sentimento de culpa com o que realmente exprimiam. 

ISSN 2675-6218

De maneira bem ampla, consoante o estudo desenvolvido por Nietzsche (1887), o que se via em relação aos delinquentes era a frieza, o distanciamento, o aumento da força de resistir, não apenas à autoridade incumbida de realizar a punição, mas de todo o complexo de pessoas que, por suas condições e desejos, levaram o indivíduo ao estado de segregação.

E é esse sentimento já existente no apenado, que viu sua vontade oprimida em detrimento dos demais e, pior ainda, que foi punido por não agir conforme os ditames sociais, que encontra solo fértil naquilo que hoje denomina-se prisão.

Não obstante a isso, é no próprio Estado que se observam as mesmas práticas delituosas em forma de procedimentos judiciais e executivos acobertadas pela legalidade (NIETZSCHE, 1887). São espionagens, fraudes, armadilhas, suborno, tudo em detrimento do ideal de justiça de um povo que não se interessa tanto pelos meios, haja vista terem superado os suplícios do século XVII e meados do XVIII (FOUCAULT, 1999), quando os ideais cristãos inseriram, no ato de punir, o respeito ao homem, tão somente com o afastamento daquele infrator do convívio com os demais.

\subsection{Dos suplícios à prisão: a falsa ideia de (re) socialização sob a ótica foucaultiana}

Analisando sob a perspectiva de Foucault (1999), o sistema de punições que vigorou entre os séculos XVII e XVIII se dava na forma de suplício corporal, por meio do qual o indivíduo era castigado fisicamente, na forma de tortura. Partindo disso, conforme o conceito de moral correta evoluía com o passar dos anos, o ato da tortura física e pública se tornou mal visto.

Logo mais à frente, a instauração do cárcere como pena, isolando o delinquente do resto da sociedade, foi a medida a ser imposta em razão das más vistas ao sistema anterior. E é nesse novo modelo de punir que surgem as questões levantadas por Foucault (1999).

O sistema de cárcere adotado impõe limitações não somente no campo físico, mas, também, no psicológico. Desde a vestimenta a o quê e quando falar, proibições dos mais diversos tipos, todas fundadas na legalidade do poder de punir do Estado. Não bastasse isso, as penitenciárias possuem seu sistema próprio, no qual os detentos mais antigos são autoritariamente superiores aos mais novos, logo, estes devem respeito não apenas aos agentes penitenciários, mas a qualquer daqueles que estejam, sistematicamente, em uma posição de liderança.

Seus corpos não são mais seus, são treinados, disciplinados, castigados e, de certo modo, transformados em máquinas (FOUCAULT, 1999). O indivíduo que adentra no sistema carcerário tende a perder-se, a ressignificar conceitos e, em razão disso, a não mais ser o mesmo. Não há, então, a ressocialização, mas a socialização, a formação de uma personalidade nova, distinta dos ideais que detinha ao entrar no cárcere.

\subsubsection{Do suplício ao cárcere: um paralelo dos meios aos fins alcançáveis}




\title{
RECIMA21 - REVISTA CIENTÍFICA MULTIDISCIPLINAR ISSN 2675-6218
}

Dito isso, ao fazer um paralelo com o método anterior, nota-se que a maior mudança não está nos fins a que se baseia, mas na forma como é feito o castigo, saindo do campo de vista da sociedade e se realizando atrás dos muros.

Nas prisões hodiernas, o ilícito não é visto por fora, o indivíduo já não ressocializa, tampouco se socializa com as normas internas, mas entende que o Estado reproduz nele tudo aquilo que prega como ruim. Conforme Nietzsche (1887, p. 44):

\begin{abstract}
Não subestimemos em que medida a visão dos procedimentos judiciais e executivos impede o criminoso de sentir seu ato, seu gênero de ação, como repreensível em si: pois ele vê o mesmo gênero de ações praticado a serviço da justiça, aprovado e praticado com boa consciência: espionagem, fraude, uso de armadilhas, suborno, toda essa arte capciosa e trabalhosa dos policiais e acusadores, e mais aquilo feito por princípio, sem o afeto sequer para desculpar, roubo, violência, difamação, aprisionamento, assassínio, tortura, tudo próprio dos diversos tipos de castigo ações de modo algum reprovadas e condenadas em si pelos juízes, mas apenas em certo aspecto e utilização prática.
\end{abstract}

Após vislumbrar a fina linha entre os suplícios e o cárcere, é evidente que a preocupação social não é a ressocialização do delinquente, tampouco a possibilidade de um dia arrepender-se daquilo que cometeu, mas sim a necessidade de se retirar do seio social aquele que perturba a ordem, não importando os meios.

Assim, ao encontrar-se em um estado de cárcere, os delinquentes, em sua maioria, não repensam suas atitudes sob a ótica de um arrependimento, mas sim naquilo que deu errado no ato (NIETZSCHE, 1887); também não reformam suas atitudes, mas veem a necessidade de se adequar ao meio, ao sistema interno, como forma de sobrevivência em um campo, até então, estranho, longe dos olhos dos bons que, assim como aqueles, pouco se importam com os que ali se encontram.

\section{DA (IN) CONSTITUCIONALIDADE DA REINCIDÊNCIA}

Sendo a agravante um resultado do fracasso da tarefa ressocializadora do Estado, cuja origem está intimamente ligada à ideia de periculosidade presumida, por conta da qual o quantum de pena é aumentado com base numa condenação anterior, questiona-se: o duplo gravame implicaria violação às garantias constitucionais?

À luz do art. $8^{\circ}$, item 4, do Pacto de São José da Costa Rica, ratificado pelo Decreto $n^{\circ}$. 678/1922, fica vedada a dupla punição por um mesmo fato delitivo. No mesmo sentido, dispõe o entendimento de Súmula $\mathrm{n}^{\circ}$. 241, do STJ, "não admitindo, para fins de dosimetria penal, que a reincidência seja valorada como circunstância agravante e judicial conjuntamente".

Destarte, o plus atribuído à nova condenação, inevitavelmente, decorrerá de uma condenação pretérita implicando afirmar, com arrimo das lições de Zaffaroni e Pierangeli (2011, p. 718), (...) "em toda agravação de pena pela reincidência existe uma violação do princípio (non) bis in idem. A pena maior que se impõe na condenação pelo segundo delito decorre do primeiro, pelo qual 


\section{RECIMA21 - REVISTA CIENTÍFICA MULTIDISCIPLINAR ISSN 2675-6218}

A (IN) CONSTITUCIONALIDADE DA REINCIDÊNCIA E A VONTADE DE PUNIR DO ESTADO ANTE O IUS PUNIENDI Murilo Cabral de Paulo Marcolino, Luan Felipe Silva Sobrinho

a pessoa já havia sido julgada e condenada". Ora, se o agente já foi devidamente julgado e condenado, qual o sentido de conferir-lhe um maior gravame a uma condenação cujo fato presente é estranho à condenação pretérita?

Além da dupla punição promovida pela reincidência, nota-se que a circunstância majorante fere outra garantia individual, qual seja, o princípio da individualização da pena, consagrado expressamente no art. $5^{\circ}$, XLVI, da Constituição Federal.

A pena é a resposta do Estado ante a ocorrência de um fato delitivo. Entretanto, a sanção deve ser calculada de forma justa e determinada ao agente infrator, observando sempre a conduta praticada; a fixação do quantum, conforme os limites legais (circunstâncias atenuantes, agravantes; causas de aumento e diminuição de pena), bem como a sua execução (CUNHA, 2016).

No que concerne ao reincidente, a majoração da pena deve ser cominada em estrita consonância com o fato delitivo. Do contrário, não seria racional sustentar o gravame baseado em critérios objetivos - a exemplo da condenação pretérita (critério mor para incidência da agravante em comento) -, os quais não guardam ligação com o caso concreto, implicando ressaltar os resquícios das influências do direito penal do autor no direito penal brasileiro (CHIQUEZI, 2009).

Ainda que a pena seja devidamente individualizada, é necessário que a sanção seja fixada e aplicada proporcionalmente ao delito praticado, para que o castigo não resulte num ato bárbaro de vingança (BECCARIA, 2014). Portanto, a pena deve guardar íntima relação com o fato criminoso. No mais, sob o prisma da majoração causada pela reincidência, o fato anterior, do qual resultou condenação transitada em julgado, se não está vinculado ao novo fato delitivo, não deve operar agravo de pena.

Ademais, quanto ao tema, é pacífico o entendimento no STF o qual, no Recurso Extraordinário $\mathrm{n}^{\circ}$. 453.000, entendeu pela constitucionalidade do instituto, ante o vigente texto da Constituição Federal, bem como a não violação dos princípios em comento. Segundo o entendimento do Supremo Tribunal Federal, a circunstância agravante decorre da habitualidade delitiva, e não de uma condenação pretérita.

\section{CONCLUSÃO}

No mais, conclui-se que o instituto da reincidência caminha na contramão das finalidades preventivas da pena, vez que o aumento à nova condenação afasta o indivíduo da (re) socialização. $\mathrm{Na}$ verdade, o que ocorre dentro dos calabouços penitenciários é, justamente, o oposto, visto que as condições a que são submetidos os presos colabora para um reforço à personalidade criminosa, na medida em que veem o estado como um inimigo, este que oprime, julga, tortura e impossibilita a reinserção à grande massa social.

Restou verificado, também, que a agravante possui influências dos bizarros dizeres do populismo penal, implicando na segregação dos indivíduos "marginalizados" em detrimento dos 
"cidadãos de bem", assim como a ultrapassada Teoria do Direito Penal do Autor, cujo alvo encontrase mirado diretamente para as características do agente, pouco importando a finalidade "utópica" das penas. Afinal, é justamente no populismo penal que há, no Estado, a busca desenfreada pela satisfação dos anseios sociais, os mesmos fundados no instinto punitivista, o qual não deveria ser aceitável por um ente superior, que está acima dos dizeres leigos.

À vista do garantismo penal, assegurado pela Magna Carta, a constitucionalidade defendida pelo Supremo Tribunal Federal parece ser bastante duvidosa, vez que a agravante promove a violação de diversas garantias constitucionais, valorando um fato estranho à nova condenação, que é desproporcional à medida que desenterra fatos anteriores para a valoração da nova pena, implicando afirmar a dissonância para com a individualização do novo delito cometido.

\section{REFERÊNCIAS}

BECCARIA, Cesare Bonessana di. Dos delitos e das penas. Tradução de Torrieri Guimarães. 6. Ed. São Paulo: Martin Claret, 2014.

BRASIL. Decreto da Lei $\mathbf{n}^{\circ}$ 2.848, de 7 dezembro de 1941. Brasília, DF: Presidência da República, 1941. Disponível em: http://www.planalto.gov.br/ccivil_03/decreto-lei/del2848compilado.htm. Acesso em: 15 set. 2020.

BRASIL. Constituição (1988). Brasília, DF: Presidência da República, 2020. Disponível em: http://www.planalto.gov.br/ccivil_03/constituicao/constituicao.htm. Acesso em: 26 out. 2020.

BRASIL. Decreto $n^{\circ}$. 678/1922. Pacto de São José da Costa Rica. Disponível em: http://www.planalto.gov.br/ccivil_03/decreto/d0678.htm. Acesso em: 26 nov. 2020.

BRASIL. Superior Tribunal de Justiça. Súmula $\mathbf{n}^{\circ}$. 241 . Disponível em: https://scon.stj.jus.br/SCON/sumstj/toc.jsp?sumula=241. Acesso em: 26 nov. 2020.

BRASIL. Supremo Tribunal Federal. Recurso Extraordinário $n^{\circ}$ 453.000/RS - Rio Grande Sul. Relator: Marco Aurélio. Pesquisa de Jurisprudência, Acórdãos, 03 de outubro de 2013. Disponível em:

https://jurisprudencia.stf.jus.br/pages/search?base=acordaos\&sinonimo=true\&plural=true\&page=1\&pa geSize=10\&queryString=reincid\%C3\%AAncia\&sort=_score\&sortBy=desc. Acesso em: 26 out. 2020.

CARVAlHo, Amilton Bueno de; CARVALHO, Salo de. Aplicação da Pena e Garantismo. 2. ed. Rio de Janeiro: Lumen Juris, 2002. Disponível em: http://arquimedes.adv.br/livros100/Aplica\%C3\%A7\%C3\%A30\%20da\%20Pena\%20e\%20Garantismo \%20-\%20Amilton\%20Bueno\%20de\%20Carvalho\%20e\%20Salo\%20de\%20Carvalho.pdf. Acesso em: 03 nov. 2020.

CHIQUEZI, Adler. Reincidência criminal e sua atuação como circunstância agravante. 2009. 157 f. Dissertação (Mestrado em Direito Penal) - Pontifícia Universidade Católica de São Paulo, São Paulo, 2009. Disponível em: http://www.dominiopublico.gov.br/download/teste/arqs/cp099252.pdf. Acesso em: 03 nov. 2020. 


\section{RECIMA21 - REVISTA CIENTÍFICA MULTIDISCIPLINAR ISSN 2675-6218}

A (IN) CONSTITUCIONALIDADE DA REINCIDÊNCIA E A VONTADE DE PUNIR DO ESTADO ANTE O IUS PUNIENDI Murilo Cabral de Paulo Marcolino, Luan Felipe Silva Sobrinho

CUNHA, Rogério Sanches. Manual de direito penal: parte geral: arts. 1 o ao 120. 4. ed. rev., ampl. e atual. Salvador: JusPODIVM, 2016. Disponível em: https://www.pdfdrive.com/manual-de-direitopenal-parte-geral-arts-1\%C2\%BA-ao-120-d158056704.html. Acesso em: 10 nov. 2020.

FOUCAULT, Michel. Vigiar e Punir: história da violência nas prisões. 27. ed. Petrópolis: Vozes, 1999. Disponível em: https://www.ufsj.edu.br/portal2repositorio/File/centrocultural/foucault_vigiar_punir.pdf. Acesso em: 13 nov. 2020.

GIL, Antonio; Como Elaborar Projetos de Pesquisa. 4. ed. São Paulo: Atlas, 2002. Disponível em: http://www.uece.br/nucleodelinguasitaperi/dmdocuments/gil_como elaborar_projeto de_pesquisa.pdf . Acesso em 13 nov. 2020.

GRECO, Rogério. Curso de Direito Penal: parte geral. 19. ed. Rio de Janeiro: Impetus, v.1, 2017. Disponível em: https://docero.com.br/doc/c85sxs. Acesso em: 15 nov. 2020.

KARAM, Maria Lúcia. Aplicação da Pena: Por uma Nova Atuação da Justiça Criminal, in RBCCrim. São Paulo: Revista dos Tribunais, $1994 . \quad$ Disponível em: https://edisciplinas.usp.br/pluginfile.php/127091/mod_resource/content/1/Maria\%20Lucia\%20Karam\% 20-\%20Aplicacao\%20da\%20pena\%20-

\%20por\%20uma\%20nova\%20atuacao\%20da\%20justica\%20criminal.pdf. Acesso em: 13 nov. 2020.

LAKATOS, Eva; MARCONI, Marina. Fundamentos de Metodologia Científica. 5. ed. São Paulo: Atlas, 2003. Disponível em: https://docero.com.br/doc/xxcsxv. Acesso em: 13 nov. 2020.

LOMBROSO, Cesare. O homem delinquente. Tradução de Sebastião José Roque. São Paulo: Ícone, $2007 . \quad$ Disponível em: https://www.academia.edu/8460215/O_Homem_Delinquente_Cesare_Lombroso. Acesso em: 20 nov. 2020.

MASSON, Cleber. Direito Penal Esquematizado: parte geral. 11. ed. São Paulo: Método, 2017. v. 1. Disponível em: https://docero.com.br/doc/xn5exc1. Acesso em: 18 nov. 2020.

NIETZSCHE, Friedrich. Genealogia da Moral. São Paulo: Editora Schwarcz LTDA, 1887. Disponível em: https://lelivros.love/book/genealogia-da-moral-friedrich-nietzsche/. Acesso em: 23 nov. 2020.

NUCCI, Guilherme de Souza. Curso de Direito Penal: parte geral: arts. $1^{\circ}$ a 120 do Código Penal. 3. ed. Rio de Janeiro: Forense, 2019. v. 1, Disponível em: https://www.academia.edu/39381559/Curso_de_Direito_Penal_I_Guilherme_Nucci. Acesso em: 25 nov. 2020.

SANTOS, Juarez Cirino dos. Direito penal: parte geral. 6. ed. ampl. e atual. Curitiba: ICPC Cursos e Edições, 2014. Disponível em: https://docero.com.br/doc/11nevn. Acesso em: 15 jan. 2021.

STRECK, Lenio Luiz. Tribunnl do júri: símbolos e rituais. 4. ed. Porto Alegre: Livraria do Advogado, 2001. Disponível em: http://arquimedes.adv.br/livros100/Tribunal\%20do\%20Juri\%20\%20Simbolos\%20e\%20Rituais\%20-\%20Lenio\%20Luiz\%20Streck.pdf. Acesso em: 05 fev. 2021.

ZAFFARONI, Eugenio Raúl; PIERANGELI, José Henrique. Manual de Direito Penal Brasileiro: parte geral. 9. ed. São Paulo: Editora Revista dos Tribunais, 2011. v.1. Disponível em: https://docero.com.br/doc/n1ex05. Acesso em: 05 fev. 2021. 